\title{
Experience in treatment of thermal burns in dogs
}

\author{
T.N. Shnyakina ${ }^{1}$, N.P. Shcherbakov ${ }^{1}$, N.M. Bryukhanchikova ${ }^{1, *}$, L.V. Medvedeva ${ }^{2}$, and \\ A.N. Bezin ${ }^{1}$ \\ ${ }^{1}$ FSBEI HE The South Ural State Agrarian University, 457100, Chelyabinsk region, Gagarina st., 13, \\ Troitsk, Russian Federation \\ ${ }^{2}$ FSBEI HE The Altai State Agrarian University, 656922, Altai Territory, Krasnoarmeisky prospect, \\ 98, Barnaul, Russian Federation
}

\begin{abstract}
Burns take 3rd place among peacetime injuries and represent a major medical and veterinary problem [1]. Effective treatment of thermal burns in animals as well as prevention of post-burn complications are an important task for a veterinarian [2]. However the treatment of animal burns in veterinary medicine has not been sufficiently developed [3]. When prescribing treatment it is necessary to take into account the degree of burn, the area and depth of damage, the presence of complications, the general condition of the animal. It is important to know that with thermal burns not only local pathological and morphological changes occur, but also general changes on the part of various organs and systems in particular protein and water-salt metabolism is disrupted, toxins accumulate, the body's defenses are decreased, and burn exhaustion is developed. In this case the degree of the general reaction of the body directly depends on the depth and area of burns [4]. Therefore the treatment should provide for anesthesia, be aimed at combating infection and intoxication of the body, and also take into account the phases of the wound process and the peculiarities of their healing [5]. For the treatment of thermal burns in animals we have proposed two methods depending on the degree of burns: a bandage method for treating second-degree burns using a complex drug mixture No. 1 and a non-bandage method for treating third-degree burns using a complex drug mixture No. 2 in combination with a short novocaine blockade. Both have shown high therapeutic efficacy.
\end{abstract}

\section{Introduction}

Thermal burn is a tissue damage resulting from contact with a liquid, solid or gaseous heat source. The first place in statistics is occupied by open flame burns (about 84\%), followed by burns with liquid substances (7\% of victims) and burns provoked by the influence of other factors (in 2\%) [6]. It should be considered that burns not only deep but also superficial, occupying more than $10 \%$ of the animal's body surface, quickly become

\footnotetext{
*Corresponding author: nina_bel@bk.ru
} 
life-threatening for the animal since in addition to local disturbances they cause general changes in the animal's body [7]. This requires both local and general treatment of the affected pet. Therefore the choice of treatment will depend on the extent and area of the burn.

A first-degree thermal burn is characterized by changes in the upper layer of the dermis. Signs of a burn at a given degree are burning, the occurrence of swelling and hyperemia in the affected area. Complete healing is noted within several days while at the site of the burn there is a complete restoration of the skin without the formation of a scar [8,9]. With burns of this degree the use of cold compresses is indicated in order to reduce the pain reaction.

Thermal burns of the second-degree appear due to prolonged exposure to high temperatures and is accompanied by burning pain, damage to the thickness of the epidermal cover and partially the papillary layer. In this case the affected animals develop blisters of various sizes filled with tissue fluid sweating from the dilated skin vessels. The blisters tend to burst and the resulting ulcers are exposed to bacterial contamination. In case of seconddegree burns after primary treatment of the burnt surface, a closed method of treatment is recommended using wet-drying dressings with antiseptic solutions that prevent the development of bacterial complications and contribute to the formation of a dry scab $[10$, $11]$.

Thermal burns of the third-degree are characterized by damage to all layers of the epidermis and papillary layer, skin necrosis - tissue necrosis which can be dry or wet. With wet necrosis dead tissue becomes a breeding ground for pathogenic microflora. In this case conservative treatment will be aimed at accelerating the rejection of necrotic tissue. For this purpose it is possible to use surgical excision of dead tissue or local treatment with drugs containing proteolytic enzymes or keratolytic agents [12].

With thermal burns of the fourth-degree charring of the entire thickness of the skin and damage to muscle and bone tissue occurs, therefore in this case necrosectomy with subsequent skin grafting is indicated against the background of the use of anti-shock, antitoxic and antiseptic therapy [13].

For burns of second, third and fourth degrees a prerequisite for treatment is analgesia with drugs of local and general effects [14].

Thus the principles and tools for the treatment of burns in animals should take into account both the extent and the area of burns $[15,16]$.

The purpose of our study was the use of methods for treating burns second andthird degrees in animals using complex medicinal mixtures and a short novocaine blockade, depending on the degree and area of the burn.

Objectives: to apply two methods for the treatment of animals with thermal burns of second andthirddegrees: a bandage method for treating second-degree burns using a complex drug mixture No. 1 and a non-bandage method for treating the third-degree burns using a complex drug mixture No. 2 in combination with a short novocaine blockade.

\section{Materials and methods}

A study and treatment of dogs admitted at different times to the clinic of the South Ural State Agrarian University of FSBEI HE was carried out 2 groups were formed: control and experimental ( 5 animals in each). Dog owners went to the clinic because of burns caused by negligence in a domestic environment. On the first day all the animals underwent mechanical cleaning of the burnt surfaces, the burnt wool and particles of foreign objects were removed, the wounds were cleaned, and cold compresses were prescribed. From 2 days after identification of second- and third-degree burns, the animals were prescribed treatment. For research the dogs with burns of the second and third degrees were selected the burn area of which was less than $10 \%$ of the total body surface. Burns of second- and 
third-degrees in dogs of the control group were once daily treated with Sulfargin ointment without the use of a bandage. In animals of the experimental group second-degree burns were treated in a closed way using a wet drying dressing, a complex medicinal mixture No. 1 was once daily applied to the fixed gauze dressing (composition: iodinol - $50 \mathrm{ml}$, Dimexide (diluted 1: 4 with distilled water) - $25 \mathrm{ml}$, chlorophyllipt $1 \%$ alcohol solution (diluted 1: 5 with distilled water) - $25 \mathrm{ml}$, novocaine - $0.5 \mathrm{~g}$ ), and third-degree burns using complex medicinal mixture No. 2 (composition: vinyline - $50 \mathrm{ml}$, chlorophyllipt $1 \%$ alcohol solution (diluted 1: 5 with distilled water) - $25 \mathrm{ml}$, lavender oil (based on vegetable oil) - $25 \mathrm{ml}$, salicylic acid - $10 \mathrm{~g}$ ) in combination with a short novocaine blockade. Treatment with mixtures was carried out once daily until complete healing of burns. Short novocaine blockade was performed once on the 2 nd day. To assess the effectiveness of treatment planimetric studies, visual assessment of regenerative processes were carried out, and the general condition of the animals was also observed. Measurement of the burn area by the method of L.N. Popova and comparison of the obtained data with the initial values. The total area of the burn in the group on the 1 st day was taken as $100 \%$, and on the subsequent days of treatment the percentage of its reduction in relation to the primary area was calculated and the dynamics of healing was determined in percentage terms. The phase of the burn process, swelling, soreness, the presence of a bacterial complication and the condition of burn wounds under the scab were visually assessed.

\section{Results and Discussions}

The indicators of planimetric studies of the burn surface in dogs of the control and experimental groups and their dynamics as a result of the treatment are presented in Table 1 .

Table 1. Dynamics of healing of burn wounds in dogs, $(M \pm m, n=5)$

\begin{tabular}{|l|c|c|c|c|c|}
\hline \multirow{2}{*}{ Group } & \multirow{2}{*}{$\begin{array}{c}\text { Degree of } \\
\text { burn }\end{array}$} & \multicolumn{4}{|c|}{ Burn area relative to initial, \% } \\
\cline { 3 - 6 } & $2^{\text {nd }}, 3^{\text {rd }}$ & 100 & $83,3 \pm 0,9$ & $10^{\text {th }}$ day & $15^{\text {th }}$ day \\
\hline Control & $5^{\text {th }}$ day & $2 \pm 2,3$ & $16,2 \pm 1,1$ \\
\hline Experienced & $2^{\text {nd }}, 3^{\text {rd }}$ & 100 & $75,7 \pm 0,8$ & $49,4 \pm 1,2^{*}$ & $9,3 \pm 0,5^{*}$ \\
\hline
\end{tabular}

* - significant differences from the control group $(\mathrm{p} \leq 0.05)$

Data analysis showed that on the 5th day of treatment burns in dogs were decreased relative to the initial data, expressed as a percentage in the control group by $16.7 \%$, in the experimental group by $24.5 \%$; on the 10 th day - by $41.8 \%$ and $53.6 \%$; on the 15 th day - by $83.8 \%$ and $90.7 \%$, respectively. The parameters of the experimental group on the 10 th and 14 th days significantly differed from the control group.

Observation of the general physiological state of the animals revealed that in the experimental group inhibition, decrease or lack of appetite and increased body temperature in animals on average by $1.2 \pm 0.1^{\circ} \mathrm{C}$ were noted from the 1 st to the 3 rd day, while in animals of the control group, these signs of a general reaction of the body, with an increase in body temperature by an average of $1.6 \pm 0.3^{\circ} \mathrm{C}$, were observed from the 1 st to the 5 th day inclusive.

Visual observation of the wound burn process showed that on the 1st day the clinical signs of burns in animals of the control and experimental groups corresponded to those of burns of second and third degrees the burned areas of the skin were reddened edematous with a painful reaction to touch and an increased local temperature.

On the 2nd day it was clinically possible to differentiate second-degree burns from third-degree burns. In some of the injured areas, small blisters were observed, filled with 
tissue fluid which is typical for second degree burns. In others a deeper damage to the skin with the presence of necrotic areas was found which is characteristic of third-degree burns.

On the 3rd day signs of exudation, inflammation, soreness, swelling, and increased local temperature were noted in the wounds of animals of both groups.

On the 5th day in the dogs of the control group the burn surfaces showed suppuration of the burned areas, of varying degrees of intensity, the edges of the burn wounds did not fit tightly to the wound surface, tenderness was noted on palpation, and inflammatory edema was pronounced. In the experimental group no signs of purulent exudation were found; in all animals thermally injured tissues began to become covered with a thin dry scab, the edges of the burn wounds were motionless and adhered tightly to the surface.

On the 10th day in the control group the soft tissues near the defect were slightly edematous and slightly painful, the burn surface was covered with a fibrous tissue not firmly seated scab, from under which a slight exudate was observed in the lower areas, the growth of granulation tissue was noted along the wound edges. In the experimental group complete cleansing of the wound surfaces from necrotic tissues was noted, an active growth of fine-grained pink granulations was noted.

On the 14th day skin defects in dogs of the control group were characterized by the absence of a scab, the bottom of the wounds was deep, rough; in the dogs of the experimental group, they had an even pink bottom, located at the level of the edges of healthy skin.

Final healing of wound defects was noted in the control group by $22 \pm 1.1$ days, in the experimental group - by $18 \pm 0.7$. At the site of third-degree burns in 3 dogs of the control group the formation of a dense scar and the absence of hair were noted. In the experimental group all animals completely recovered the hairline at the site of the burned areas.

\section{Conclusions}

Our studies on the treatment of thermal burns in dogs show that as a result of the use of a bandage method for treating second degree burns using a complex mixture No. 1 and a method for treating third degree burns using a complex drug mixture No. 2 in combination with a short novocaine blockade, they showed a high therapeutic effectiveness. In animals of the experimental group wound healing occurred faster, without complications from secondary infection. In the control group animals showed a slowdown in the healing process, suppuration of wounds which required mechanical removal of necrotic tissue from wounds and slowed down the healing process.

As a result of the study it was found that the proposed medicinal mixtures have analgesic, regenerating, decongestant and bactericidal properties in comparison with the traditionally used drugs.

\section{References}

1. N.M. Bezina, Clinical and hematological status of dogs in the treatment of burn injury, materials of the International Scientific and Practical Conference: Veterinary medicine - to the agro-industrial complex. Troitsk, 35-39 (2017)

2. N.M. Bezina, T.N. Shnyakina, Microbiological studies of the wound surface in the treatment of burns in animals, Materials of the International Scientific and Practical Conference of the Institute of Veterinary Medicine: Problems of Veterinary Medicine, Veterinary and Sanitary Expertise, Biotechnology and Animal Science at the Present 
Stage of Development of the Russian Agroindustrial Complex, Chelyabinsk, 18-22 (2018)

3. E.L. Bezruk, Bulletin of the Altai State Agrarian University, 7(189), 87-95 (2020)

4. S.V. Pozyabin, Yu.I. Filippov, N.A. Kozlov, A.A. Stekolnikov, Yu.A. Vatnikov, V.V. Belogurov, M.D. Kachalin, General veterinary surgery, 752 (Moscow, Kolos-s, 2019)

5. E.I. Veremeya, B.S. Semenov, Operative surgery with topographic anatomy, 560 (St. Petersburg, Kvadro, 2012)

6. A.N. Pereverzev, V.A. Tolkachev, Dynamics of the healing of burn trauma during the application of the drug "Acerbin", materials of the National (All-Russian) scientific and practical conference: Actual problems of youth science in the development of the agro-industrial complex, Kursk, 224-228 (2019)

7. I.V. Revyakin, L.V. Medvedeva, V.A. Petrenko, Bulletin of the Altai State Agrarian University, 9(155), 165-170 (2017)

8. N.V. Ostrovsky, V.V. Petrov, A.S. Bystrova, M.V. Musatskova, Basic research, 6, 512-515 (2014)

9. S.V. Timofeev, E.V. Zhilyakova, V.V. Belogurov, Veterinary Medicine, 1, 52-53 (2006)

10. S.V. Chernigov, N.V. Zubkova, Yu.V. Chernigov, Planimetric analysis as a method for assessing burn wound healing in experimental animals, materials of the scientific and practical conference: Digital agriculture of the region: main tasks, promising areas and systemic effects, Omsk, 245-249 (2019)

11. S.V. Chernigov, N.V. Zubkova, Yu.V. Chernigov, A.V. Gorbatenko, Bulletin of KrasSAU, 7(148), 123-130 (2019)

12. T.N. Shnyakina, N.M. Bezina, Experimental method of treating burn injury in dogs, materials of the international scientific-practical conference: Innovative activity in the modernization of the agro-industrial complex, Kursk, 278-281 (2016)

13. W.B. Sheng, G. Dong, Y. Wan, L. Yao, H. Tang, Z. Xia, Zhonghua Shao Shang Za Zhi., 30(4), 353-355 (2014) https://www.ncbi.nlm.nih.gov/pubmed/25429817.

14. I. Kaddoura, G. Abu-Sittah, R. Karamanoukian, N. Papazian, Ann Burns Fire Disasters, 30 (2), 95-102 (2017)

15. T.N. Shnyakina, N.M. Bezina, N.P. Shcherbakov, L. V. Chernyshova, T.N. Makarova, I.R. Kanagina, L.V. Medvedeva, International Transaction Journal of Engineering, Management and Applied Sciences and Technologies, 11(14), 11A14H (2020)

16. Y. Benchamkha, O. Dhaidah, A. Dahazze, Q. Meriem, M. D. Elamrani and S. Ettalbi, J. Burns Trauma, 7 (6), 72-79 (2017) 